\title{
Ecological association between operative vaginal delivery and obstetric and birth trauma
}

\author{
Giulia M. Muraca PhD MPH, Sarka Lisonkova MD PhD, Amanda Skoll MD, Rollin Brant PhD, \\ Geoffrey W. Cundiff MD, Yasser Sabr MD MHSc, K.S. Joseph MD PhD
}

Cite as: CMAJ 2018 June 18;190:E734-41. doi: 10.1503/cmaj.171076

See related article at www.cmaj.ca/lookup/doi/10.1503/cmaj.180668

\begin{abstract}
BACKGROUND: Increased use of operative vaginal delivery (use of forceps, vacuum or other device) has been recommended to address high rates of cesarean delivery. We sought to determine the association between rates of operative vaginal delivery and obstetric trauma and severe birth trauma.
\end{abstract}

METHODS: We carried out an ecological analysis of term, singleton deliveries in 4 Canadian provinces (2004-2014) using data from the Canadian Institute for Health Information. The primary exposure was mode of delivery. The primary outcomes were obstetric trauma and severe birth trauma.
RESULTS: Data on 1938913 deliveries were analyzed. The rate of obstetric trauma was $7.2 \%$ in nulliparous women, and $2.2 \%$ and $2.7 \%$ among parous women without and with a previous cesarean delivery, respectively, and rates of severe birth trauma were 2.1, 1.7 and 0.7 per 1000 , respectively. Each $1 \%$ absolute increase in rates of operative vaginal delivery was associated with a higher frequency of obstetric trauma among nulliparous women (adjusted rate ratio [ARR] 1.06, 95\% confidence interval [CI] 1.05-1.06), parous women without a previous cesarean delivery (ARR 1.10, 95\% Cl 1.08-1.13) and parous women with a previous cesarean delivery (ARR 1.11, 95\% Cl 1.07-1.16). Operative vaginal delivery was associated with more frequent severe birth trauma, but only in nulliparous women (ARR 1.05, 95\% Cl 1.031.07). In nulliparous women, sequential vacuum and forceps instrumentation was associated with the largest increase in obstetric trauma (ARR 1.44, 95\% $\mathrm{Cl} 1.35-1.55)$ and birth trauma (ARR $1.53,95 \% \mathrm{Cl} 1.03-2.27$ ).

INTERPRETATION: Increases in population rates of operative vaginal delivery are associated with higher population rates of obstetric trauma, and in nulliparous women with severe birth trauma.

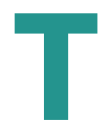

he increase in cesarean delivery over the past several decades has occurred concomitantly with a decline in operative vaginal deliveries. In the United States, operative vaginal delivery rates decreased from $9.4 \%$ in 1995 to $3.1 \%$ of all deliveries in 2015, whereas cesarean delivery rates increased from $20.8 \%$ to $32.0 \% .^{1,2}$ In Canada as well, rates of operative vaginal delivery followed the same downward trajectory, from $16.8 \%$ of all vaginal deliveries in 1995 to $13.2 \%$ in $2014,{ }^{3,4}$ whereas cesarean delivery rates increased from $17.6 \%$ to $27.3 \%$ of all deliveries. This inverse relationship has led to recommendations for increasing rates of operative vaginal delivery as a solution for addressing the high rates of cesarean delivery. ${ }^{5}$

Such recommendations for addressing increases in cesarean delivery are premised on the assumption that operative vaginal delivery has greater relative safety compared with cesarean delivery. However, recent studies ${ }^{6-9}$ have shown higher rates of severe perinatal and maternal adverse outcomes after operative vaginal delivery. In particular, our previous work ${ }^{6,7}$ showed substantially higher rates of obstetric trauma among midpelvic forceps and vac- uum deliveries, compared with cesarean deliveries (adjusted rate ratio [ARR] 8.48, 95\% confidence interval [CI] 7.22-9.96 and 6.90, $95 \% \mathrm{Cl} 5.86-8.13$, respectively). The ARRs for severe birth trauma were $4.33,95 \% \mathrm{Cl} 2.31-8.11$ for forceps and 3.16, 95\% Cl 1.65-6.05 for vacuum versus cesarean delivery. ${ }^{7}$ Nevertheless, the populationlevel impact of increasing the rate of operative vaginal delivery on obstetric and birth trauma rates has not been quantified.

We sought to characterize temporal trends in obstetric trauma and severe birth trauma in Canada, by mode of delivery, by operative instrument (i.e., forceps or vacuum) and by pelvic station (outlet, low or midpelvic). We also aimed to quantify the associations between population rates of operative vaginal delivery and obstetric trauma and severe birth trauma.

\section{Methods}

We obtained data on all hospital deliveries in 4 Canadian provinces - Alberta, Manitoba, Ontario and Saskatchewan - from the Canadian Institute for Health Information's Discharge Abstract Database. 
We excluded deliveries that occurred in the other provinces and territories in Canada because of a lack of detailed information on parity. Trained health records personnel abstracted information from medical records in the Discharge Abstract Database using standardized definitions, and data accuracy was ensured through routine quality assurance checks. Information in the database included details regarding medical history, maternal characteristics, labour and delivery, and neonatal condition, and details of diagnoses and interventions or procedures. Diagnoses and procedures in the database (e.g., obstetric trauma, forceps delivery) represent notations in the medical chart made by physicians and were coded using the Canadian version of the International Classification of Diseases (ICD10-CA) and the Canadian Classification of Interventions. The accuracy of perinatal information in the database has been validated..$^{10,11}$ In particular, maternal morbidity, such as severe perineal lacerations, had a high sensitivity and specificity (sensitivity for third- and fourth-degree perineal lacerations was $97.1 \%$ and $94.7 \%$, respectively, and the specificity for both diagnoses was $99.9 \%) .{ }^{10}$ Furthermore, a 2015/16 Discharge Abstract Database reabstraction study showed high agreement for obstetric trauma indicators $(97.0 \%$ agreement, $95 \% \mathrm{Cl} 95.4 \%-98.6 \%) .{ }^{11}$ Severe perinatal morbidity in the neonate, such as intraventricular hemorrhage, had a sensitivity of $88.9 \%$ and a specificity of $100 \%$, and fracture of the clavicle had a sensitivity of $91.7 \%$ and a specificity of $100 \% .^{10}$

All hospital deliveries between 37 and 41 weeks' gestation that resulted in a singleton live birth between April 2004 and March 2015 were included in the study (fiscal years 2004-2014). We grouped operative vaginal deliveries into 3 categories based on pelvic station: outlet, low-pelvic and midpelvic. ${ }^{12}$

The 2 primary outcomes were obstetric trauma and severe birth trauma. Obstetric trauma included severe perineal lacerations (third- and fourth-degree), cervical and high vaginal lacerations, pelvic hematoma (perineum, vagina or vulva), obstetric injury to the pelvic organs, pelvic joints or ligaments, injury to the bladder or urethra, laceration to the broad ligament of the uterus, extension of the uterine incision, wound dehiscence and other obstetric trauma. Severe birth trauma included intracranial hemorrhage and laceration, skull fracture, severe injury to the central or peripheral nervous system, fracture of the long bones and injury to the liver or spleen. The inclusion and exclusion criteria, confounders and outcomes are listed in Appendix 1 (available at www.cmaj.ca/lookup/suppl/doi:10.1503/cmaj.171076/-/DC1).

\section{Statistical analysis}

We categorized women by parity and obstetric history into 3 strata: nulliparous women, parous women without a previous cesarean delivery and women with a previous cesarean delivery. Within each of these strata, we assessed temporal trends in obstetric and severe birth trauma by mode of delivery, operative instrument and pelvic station using the Cochran-Armitage test for linear trend in proportions by year and by comparing rates in 2014 with those in 2004. We estimated ARRs and 95\% Cls using ecological random-intercept Poisson regression models to quantify the associations between rates of operative vaginal delivery and obstetric trauma and severe birth trauma, while addressing clustering of observations at the province-year level. We used stratified analyses to quantify the effects of instruments (forceps, vacuum, sequential instrumentation) and the pelvic station at which the operative vaginal delivery was attempted, while adjusting for confounders - namely, maternal age, hypertensive disorders, diabetes, labour induction, macrosomia and year of delivery. Each province-year represented 1 unit of analysis, resulting in 44 units in each of the 3 strata $(n=132)$. The number of cases of obstetric trauma (or severe birth trauma) in each province-year served as the outcome and these were offset by the number of live births in that province-year. We conducted all analyses using SAS version 9.4 for Windows (SAS Institute Inc., Cary, NC).

\section{Ethics approval}

Ethics approval for the study was obtained from the Clinical Research Ethics Board at the University of British Columbia (H14-02746).

\section{Results}

The study population included 1938913 term, singleton deliveries. Temporal trends in the rates of operative vaginal delivery, obstetric trauma and severe birth trauma over the study period are shown in Appendix 2 (available at www.cmaj.ca/lookup/suppl/doi:10.1503/ cmaj.171076/-/DC1). The rates of operative vaginal delivery and cesarean delivery were $18.2 \%$ and $26.6 \%$, respectively, in nulliparous women; $5.5 \%$ and $6.7 \%$, respectively, in parous women with no previous cesarean delivery; and $3.4 \%$ and $81.9 \%$ in women with a previous cesarean delivery (Table 1 ). The rate of obstetric trauma was $7.2 \%$ among nulliparous women, $2.2 \%$ among parous women without a previous cesarean delivery, and $2.7 \%$ among women with a previous cesarean delivery, and the rate of severe birth trauma was 2.1, 1.7 and 0.7 per 1000 deliveries in the 3 groups, respectively (Appendix 3, available at www.cmaj.ca/lookup/suppl/doi:10.1503/ cmaj.171076/-/DC1). Most cases of obstetric trauma among operative vaginal deliveries were a result of severe perineal lacerations $(86.3 \%)$, and injury to the bladder or urethra (44.5\%) and repair required for the uterine incision $(27.3 \%)$ constituted the most frequent obstetric traumas among cesarean deliveries (Table 2). Severe birth trauma after operative vaginal delivery was mostly a result of brachial plexus injury among both operative vaginal deliveries (64.9\%) and cesarean deliveries (30.4\%; Table 3). Injury to the femur or humerus was also common among cesarean deliveries (22.7\%).

\section{Temporal trends in obstetric trauma}

Obstetric trauma rates increased significantly among nulliparous women, from $6.6 \%$ of deliveries in 2004 to $7.2 \%$ in 2014 ( $p<0.001$ ), and among women with a previous cesarean delivery, from $2.5 \%$ to $3.0 \%(p<0.001$; Figure $1 \mathrm{~A})$. The increased rate of obstetric trauma was most pronounced among operative vaginal deliveries, with rates increasing from $16.6 \%$ to $19.4 \%$ among nulliparous women $(p<0.0001$; Figure $1 \mathrm{~B})$ and from $13.8 \%$ to $18.7 \%$ among women with a previous cesarean delivery ( $p=0.0001$; Figures 1B-1D).

Obstetric trauma rates stratified by operative instrument showed the largest increases among forceps deliveries in nulliparous women (19.4\% in 2004 to $26.5 \%$ in 2014; $p<0.0001$; Appendix 4, supplemental Figure S2A, available at www.cmaj.ca/lookup/suppl/doi:10.1503/ cmaj.171076/-/DC1), parous women without a previous cesarean 
Table 1: Distribution of mode of delivery by maternal, obstetric and infant characteristics*

\begin{tabular}{|c|c|c|c|c|c|}
\hline $\begin{array}{l}\text { Maternal, obstetric or } \\
\text { infant characteristic }\end{array}$ & $\begin{array}{l}\text { No. of spontaneous } \\
\text { vaginal deliveries (\%) }\end{array}$ & $\begin{array}{c}\text { No. of operative } \\
\text { vaginal deliveries (\%) }\end{array}$ & $\begin{array}{c}\text { Std. diff } † \\
\text { operative vaginal } \\
\text { delivery v. } \\
\text { spontaneous } \\
\text { vaginal delivery }\end{array}$ & $\begin{array}{c}\text { No. of cesarean } \\
\text { deliveries }(\%)\end{array}$ & $\begin{array}{c}\text { Std. diff } \dagger \\
\text { cesarean } \\
\text { delivery v. } \\
\text { spontaneous } \\
\text { vaginal delivery }\end{array}$ \\
\hline Totals & $1234877(63.7)$ & $207675(10.7)$ & - & $496361(25.6)$ & - \\
\hline Nulliparous women & $463702(37.6)$ & $152632(73.5)$ & - & $223438(45.0)$ & - \\
\hline $\begin{array}{l}\text { Advanced maternal age } \\
(\geq 35 \mathrm{yr})\end{array}$ & $38215(8.2)$ & $18029(11.8)$ & 0.12 & 39525 (17.7) & 0.29 \\
\hline Hypertensive disorders & $27171(5.9)$ & $9785(6.4)$ & 0.02 & $22852(10.2)$ & 0.16 \\
\hline Diabetes & 16097 (3.5) & $6562(4.3)$ & 0.04 & $15038(6.7)$ & 0.15 \\
\hline Induction of labour & $118773(25.6)$ & $44658(29.3)$ & 0.08 & 73761 (33.0) & 0.16 \\
\hline Macrosomia (> $4000 \mathrm{~g}$ ) & $35791(7.7)$ & 14687 (9.6) & 0.07 & $37590(16.8)$ & 0.28 \\
\hline $\begin{array}{l}\text { Parous women with no } \\
\text { previous cesarean } \\
\text { delivery }\end{array}$ & 732448 (59.3) & $45983(22.1)$ & - & $56185(11.3)$ & - \\
\hline $\begin{array}{l}\text { Advanced maternal age } \\
(\geq 35 \mathrm{yr})\end{array}$ & $156413(21.4)$ & $12742(27.7)$ & 0.15 & $18258(32.5)$ & 0.25 \\
\hline Hypertensive disorders & 25371 (3.5) & $1955(4.3)$ & 0.04 & $3513(6.3)$ & 0.13 \\
\hline Diabetes & $34580(4.7)$ & $2783(6.1)$ & 0.06 & $5108(9.1)$ & 0.17 \\
\hline Induction of labour & 173213 (23.6) & $13081(28.5)$ & 0.11 & $10908(19.4)$ & -0.10 \\
\hline Macrosomia (> $4000 \mathrm{~g}$ ) & $101343(13.8)$ & $7247(15.8)$ & 0.06 & $10318(18.4)$ & 0.13 \\
\hline $\begin{array}{l}\text { Parous women with a } \\
\text { previous cesarean } \\
\text { delivery }\end{array}$ & $38727(3.1)$ & $9060(4.4)$ & - & $216738(43.7)$ & - \\
\hline $\begin{array}{l}\text { Advanced maternal age } \\
\text { ( } \geq 35 \mathrm{yr} \text { ) }\end{array}$ & $9611(24.8)$ & $2333(25.8)$ & 0.02 & $68361(31.5)$ & 0.15 \\
\hline Hypertensive disorders & $1111(2.9)$ & $232(2.6)$ & -0.02 & $8126(3.8)$ & 0.05 \\
\hline Diabetes & $2021(5.2)$ & $441(4.9)$ & -0.01 & $16933(7.8)$ & 0.11 \\
\hline Induction of labour & $6595(17.0)$ & $1416(15.6)$ & -0.04 & $3692(1.7)$ & -0.54 \\
\hline Macrosomia (> $4000 \mathrm{~g}$ ) & $4699(12.1)$ & $1047(11.6)$ & -0.02 & $26223(12.1)$ & 0.00 \\
\hline
\end{tabular}

delivery $(10.3 \%$ to $14.3 \% ; p=0.0001$; Appendix 4, supplemental Figure $\mathrm{S} 2 \mathrm{~B})$ and parous women with a previous cesarean delivery (16.6\% to 25.5\%, $p=0.02$; Appendix 4, supplemental Figure S2C). The rate of obstetric trauma increased significantly at low-pelvic station among all groups, regardless of parity or obstetric history $(p<0.0001$ for all 3 groups; Appendix 5, available at www.cmaj.ca/lookup/suppl/ doi:10.1503/cmaj.171076/-/DC1).

\section{Temporal trends in severe birth trauma}

Overall rates of severe birth trauma did not change appreciably in nulliparous or parous women (Figure 2). However, among women who had an operative vaginal delivery, the rate of severe birth trauma increased significantly among nulliparous women (from 4.5 in 2004 to 6.8 per 1000 deliveries in 2014; $p=0.0001$; Figure 2B) and parous women without a previous cesarean delivery (from 6.5 to 10.6 per 1000 deliveries; $p<0.01$; Figure $2 \mathrm{C}$ ). In nulliparous women, the increase in severe birth trauma was most pronounced among deliveries with sequential instrument application (7.4 in 2004 and 14.3 per 1000 deliveries in 2014; $p=0.01$; Appendix 6, supplemental Figure S4A, available at www.cmaj.ca/lookup/suppl/doi:10.1503/ cmaj.171076/-/DC1) and among operative vaginal deliveries at outlet pelvic station ( 2.1 to 9.2 per 1000 deliveries; $p=0.04$; Appendix 7 , supplemental Figure S5A, available at www.cmaj.ca/lookup/suppl/ doi:10.1503/cmaj.171076/-/DC1). Linear trends in the rate of severe birth trauma by operative instrument and pelvic station were not significant among parous women (Appendix 6, supplemental Figures S4B and S4C, and Appendix 7, supplemental Figures S5B and S5C).

\section{Association between operative vaginal delivery and obstetric trauma}

In nulliparous women, the rate of operative vaginal delivery was positively associated with obstetric trauma (ARR 1.06, 95\% Cl 1.05-1.06; 
Table 2: Distribution of components of composite obstetric trauma outcome by mode of delivery*

\section{Outcome}

\section{All obstetric trauma}

Severe perineal lacerations

(3rd and 4th degree)

Injury to bladder or urethra

High vaginal laceration

Cervical laceration

Other obstetric injury

Repair of uterine incision

Delayed repair of episiotomy or repair of wound dehiscence after episiotomy or obstetrical laceration repair

Hematoma of the pelvis

(perineum, vagina or vulva)

Injury to the pelvic joints and ligaments

Laceration to the broad ligament of the

uterus

Repair of wound dehiscence after

cesarean delivery

\section{No. of operative \\ vaginal deliveries $(\%)$ \\ $n=207675$}

$n=1938913$

$85842(100)$

$60970(71.0)$

$5774(6.7)$

$5039(5.8)$

$4530(5.3)$

$3306(3.9)$

$2473(2.9)$

2447 (2.9)

$2180(2.5)$

$1186(1.4)$

$492(0.6)$

$514(0.6)$
$33095(100)$

$28550(86.3)$

$341(1.0)$

$2015(6.1)$

$758(2.3)$

507 (1.5)

$39(0.1)$

$1056(3.2)$

$487(1.5)$

$154(0.5)$

$9(0.0)$

$14(0.0)$
No. of cesarean

deliveries (\%)

$n=496361$

$8395(100)$

$39(0.5)$

$3735(44.5)$

205 (2.4)

$892(10.6)$

$1105(13.2)$

$2296(27.3)$

$47(0.6)$

$262(3.1)$

$447(5.3)$

$439(5.2)$

$471(5.6)$
No. of spontaneous

vaginal deliveries $(\%)$ $n=1234877$

$44352(100)$

$32381(73.0)$

$1698(3.8)$

$2771(6.2)$

$2857(6.4)$

$1694(3.8)$

$138(0.3)$

$1344(3.0)$

$1431(3.2$

$585(1.3)$

$44(0.1)$

$29(0.1)$

${ }^{*}$ The sum of individual trauma components may exceed the total because some deliveries had multiple trauma diagnoses.

\section{Table 3: Distribution of components of composite severe birth trauma outcome by mode of delivery*}

\begin{tabular}{|c|c|c|c|c|}
\hline Outcome & $\begin{array}{c}\text { All deliveries (\%) } \\
n=1938913\end{array}$ & $\begin{array}{l}\text { No. of operative } \\
\text { vaginal deliveries (\%) } \\
\qquad n=207675\end{array}$ & $\begin{array}{c}\text { No. of cesarean } \\
\text { deliveries (\%) } \\
n=496361\end{array}$ & $\begin{array}{c}\text { No. of spontaneous } \\
\text { vaginal deliveries (\%) } \\
\qquad n=1234877\end{array}$ \\
\hline All severe birth trauma & $3366(100)$ & $1356(100)$ & 326 (100) & $1684(100)$ \\
\hline $\begin{array}{l}\text { Severe peripheral nervous system injury } \\
\text { (brachial plexus injury) }\end{array}$ & $2352(69.9)$ & 880 (64.9) & $99(30.4)$ & $1373(81.5)$ \\
\hline Femur or humerus injury & $443(13.2)$ & $139(10.3)$ & $74(22.7)$ & $230(13.7)$ \\
\hline Subaponeurotic hemorrhage & $244(7.2)$ & $191(14.1)$ & $37(11.3)$ & $16(1.0)$ \\
\hline Intracranial hemorrhage or laceration & $226(6.7)$ & $123(9.1)$ & $57(17.5)$ & $123(7.3)$ \\
\hline Skull fracture & $104(3.1)$ & $47(3.5)$ & $48(14.7)$ & $9(0.5)$ \\
\hline $\begin{array}{l}\text { Severe central nervous system injury } \\
\text { (brain damage or spinal cord injury) }\end{array}$ & $101(3.0)$ & $34(2.5)$ & $31(9.5)$ & $36(2.1)$ \\
\hline Injury to the liver or spleent & $<5(<0.1)$ & $<5(<0.4)$ & $<5(<16.9)$ & $<5(<0.3)$ \\
\hline
\end{tabular}

Table 4). This association was significantly stronger in parous women with and without a previous cesarean delivery (ARRs $1.11,95 \% \mathrm{Cl}$ 1.07-1.16 and 1.10, 95\% Cl 1.08-1.13, respectively).

The ARR expressing the association between the rate of forceps and obstetric trauma in nulliparous women was 1.09 (95\% Cl 1.081.10), and the ARR for vacuum delivery was 1.06 (95\% Cl 1.051.07). Among parous women, the ARRs for the association between forceps or vacuum and obstetric trauma were similar to those in nulliparous women. However, deliveries after the use of sequential instruments were not significantly associated with the rate of obstetric trauma in either group of parous women. Operative vaginal deliveries at outlet, low-pelvic and midpelvic station were positively associated with obstetric trauma in nulliparous and parous women (Table 4). 
A

All deliveries

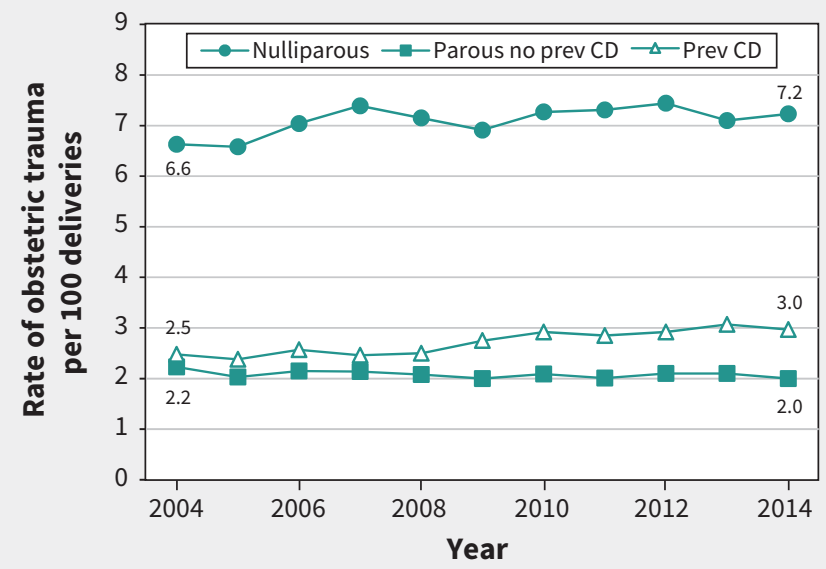

C

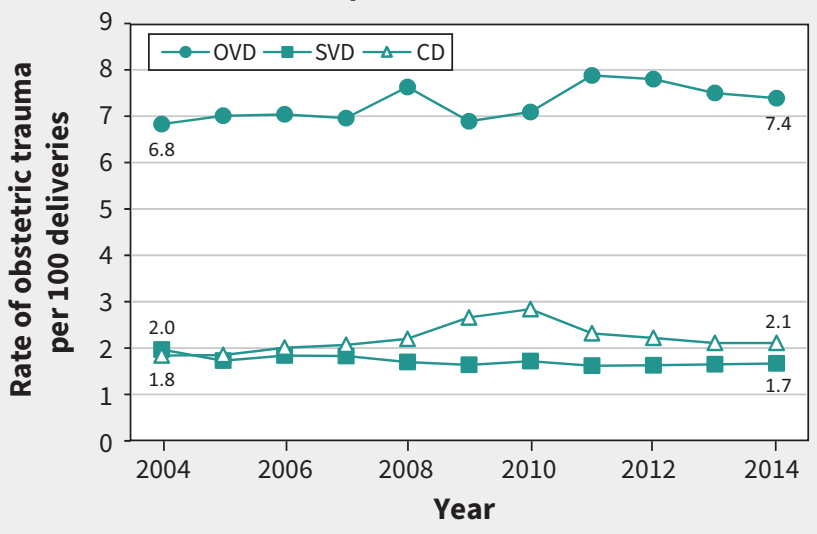

B Nulliparous

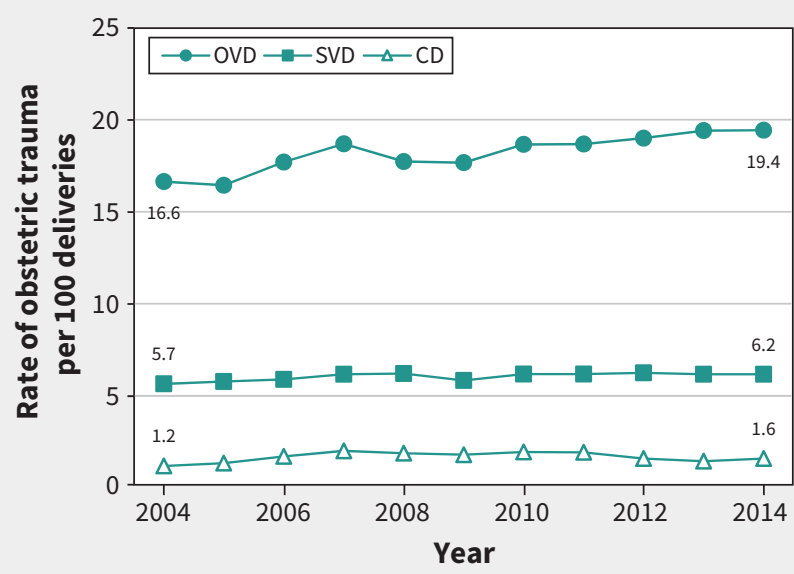

D

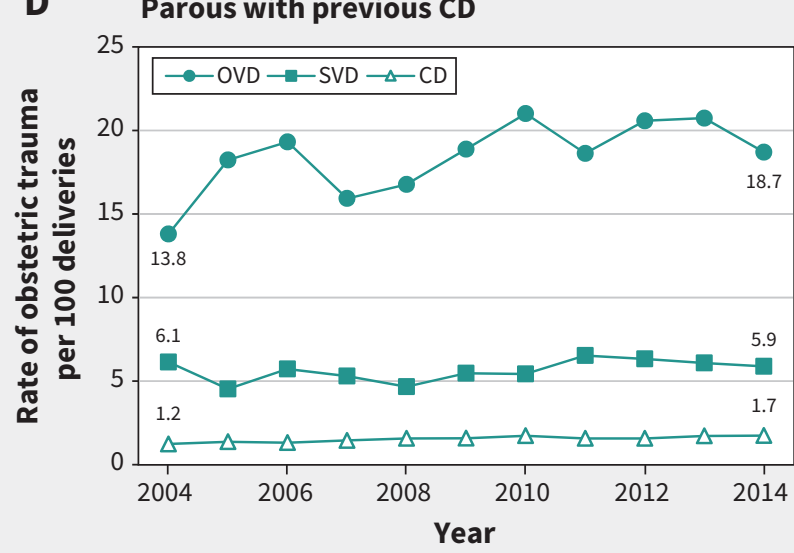

Figure 1: Temporal trends in obstetric trauma stratified by parity and obstetric history (A), stratified by mode of delivery among nulliparous women (B), among parous women without a previous cesarean delivery (C), among women with a previous cesarean delivery (D), among term, singleton deliveries, Canada, 2004-2014. Using the Cochran-Armitage test for linear trend in proportions, $p<0.001$ for overall obstetric trauma trend among nulliparous and parous women (with and without a previous cesarean delivery); $p<0.001$ for obstetric trauma trend among operative vaginal delivery in all 3 groups; $p<0.0001,0.03$, and 0.01 for obstetric trauma trend among spontaneous vaginal delivery in nulliparous women, parous women without cesarean delivery, and women with a previous cesarean delivery, respectively; and $p=0.2,0.07$ and $<0.0001$ for these trends in cesarean delivery among the same 3 groups, respectively. Note: $C D=$ cesarean delivery, $O V D=$ operative vaginal delivery, $S V D=$ spontaneous vaginal delivery.

Calculations based on the number of term, singleton live births in Canada in $2015-16^{13}$ showed that a $1 \%$ increase in the rate of operative vaginal delivery would result in about 708,360 and 158 excess cases of obstetric trauma per year in nulliparous women, parous women without a previous cesarean delivery, and parous women with a previous cesarean delivery, respectively (Table 4).

\section{Association between operative vaginal delivery and severe birth trauma}

Operative vaginal delivery rates were positively associated with severe birth trauma only in nulliparous women (ARR 1.05, 95\% Cl 1.03-1.07) and only with sequential instrumentation (ARR 1.53, $95 \% \mathrm{Cl}$ 1.03-2.27; Table 4). Pelvic station-specific rates of operative vaginal delivery were positively associated with severe birth trauma at low-pelvic station (ARR 1.06, 95\% $\mathrm{Cl} 1.01-1.12$ ) and midpelvic station (ARR 1.04, 95\% Cl 1.01-1.07; Table 4). The absolute increase in the rate of severe birth trauma per $1 \%$ increase in the rate of operative vaginal delivery was 0.11 per 1000 deliveries to nulliparous women, which would result in about 18 excess cases of severe birth trauma in Canada annually. ${ }^{13}$

\section{Interpretation}

Our study showed that the rate of obstetric trauma has increased in Canada in recent years. This increase was concentrated among operative vaginal deliveries, particularly in forceps deliveries among nulliparous women and women who had a previous cesarean delivery. The rate of severe birth trauma also increased among operative vaginal deliveries in nulliparous women and parous women without a previous cesarean delivery. Additionally, our study showed positive associations between the rate of operative vaginal delivery and obstetric trauma after 
A All deliveries

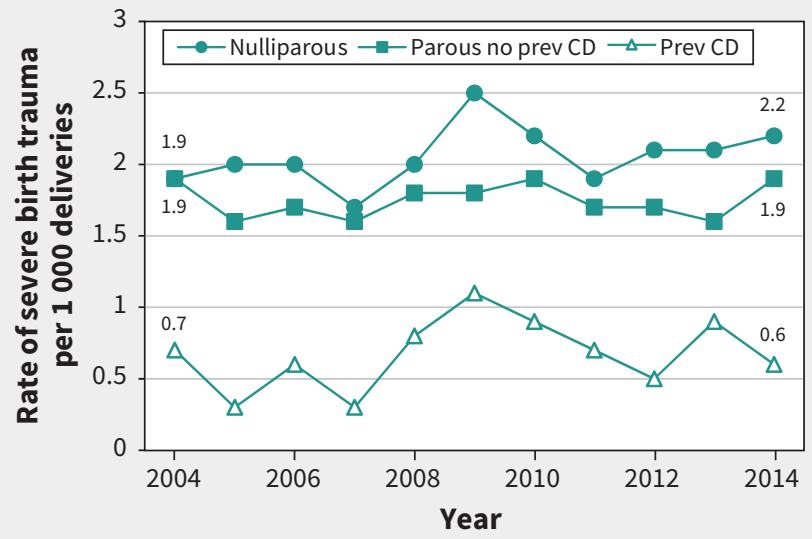

C

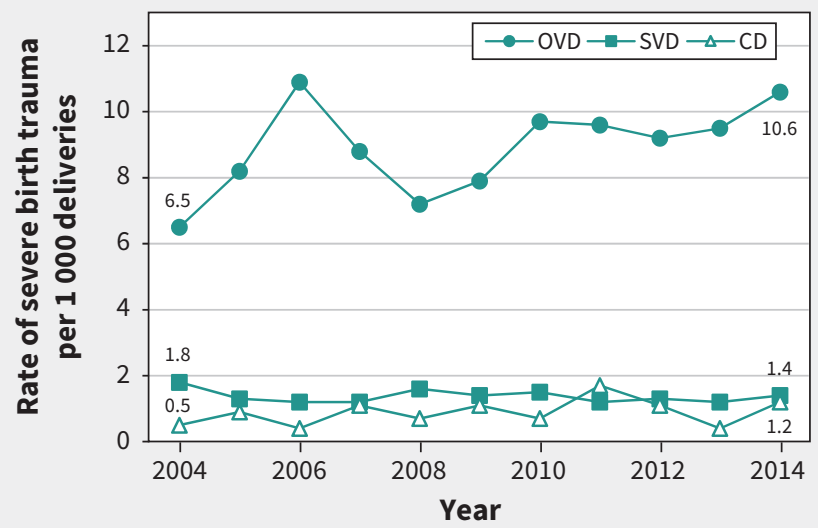

B Nulliparous

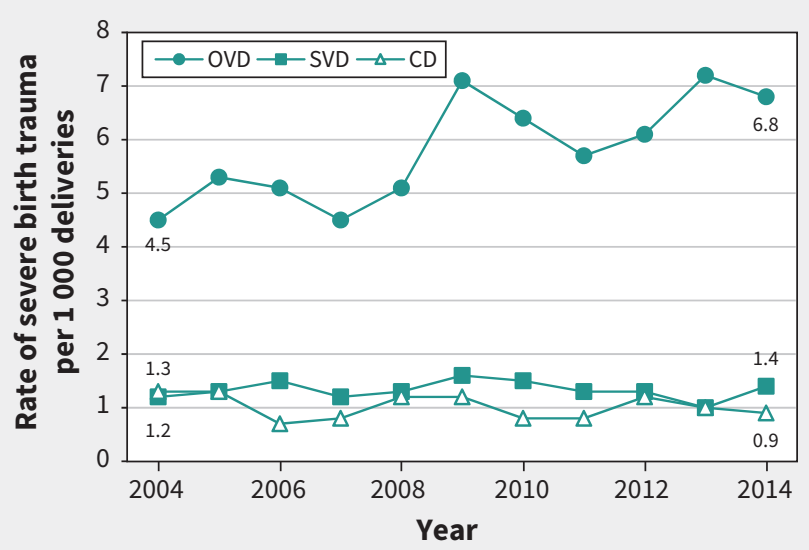

D Parous with previous CD

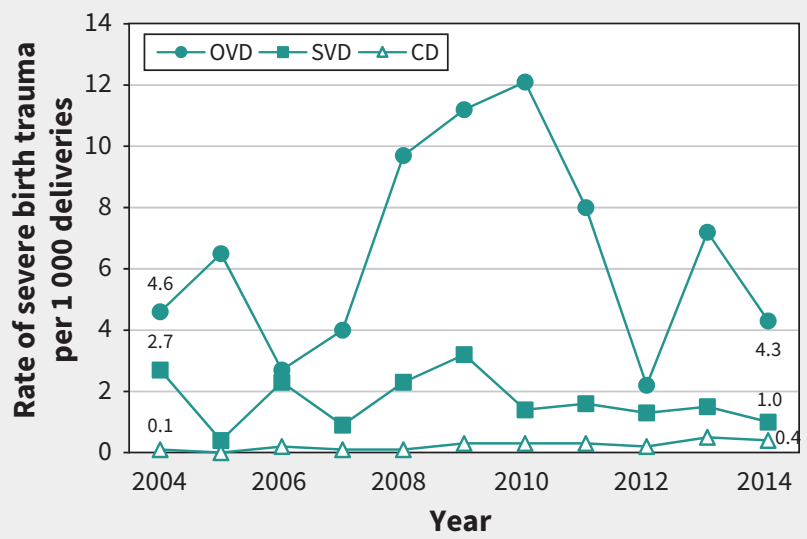

Figure 2: Temporal trends in severe birth trauma stratified by parity and obstetric history (A), stratified by mode of delivery among nulliparous women (B), among parous women without a previous cesarean delivery (C), among women with a previous cesarean delivery (D), among term, singleton deliveries, Canada, 2004-2014. Using the Cochran-Armitage test for linear trend in proportions, $p=0.0001$ for the trend in severe birth trauma in operative vaginal delivery among nulliparous women. All other $p$ values for severe birth trauma trend $>0.05$. Note: $C D=$ cesarean delivery, OVD $=$ operative vaginal delivery, SVD = spontaneous vaginal delivery.

adjustment for known confounders. The associations between operative vaginal delivery and obstetric trauma were significantly stronger among parous than among nulliparous women. The rate of operative vaginal delivery was also positively associated with severe birth trauma in nulliparous women, but not in parous women. These findings show the potential population-level impact of attempts to increase the use of operative vaginal delivery.

Third- and fourth-degree perineal lacerations, or obstetric anal sphincter injury, represented most of the obstetric trauma cases among women with operative vaginal delivery. Quality-of-life impairments after obstetric anal sphincter injury include perineal pain, dyspareunia and sexual dysfunction, abscess formation, wound breakdown and rectovaginal fistulae. ${ }^{14}$ Perhaps the most disabling complication is anal incontinence, and obstetric anal sphincter injury is the most common cause of anorectal symptoms in women. ${ }^{15}$ The reported rates of anal incontinence after the primary repair of obstetric anal sphincter injury range between 15\% and $61 \%$, with a mean of $39 \%,{ }^{15}$ and these rates increase with time, up to $54 \%$ at $3-8$ years after delivery. ${ }^{16}$ Moreover, there is accumulating evidence of a positive association between the rate of operative vaginal delivery and subsequent rates of surgery for pelvic organ prolapse. ${ }^{17}$ The benefit versus risk profile of operative vaginal delivery may therefore require re-evaluation in light of these longterm effects.

\section{Comparison with other studies}

The rates of obstetric trauma in our study are consistent with rates reported from other provinces of Canada, ${ }^{18}$ as well as from the United Kingdom. ${ }^{19}$ The temporal increase in obstetric trauma we observed in this study did not parallel obstetric trauma trends in the US; the obstetric trauma rate in Washington state decreased from $6.7 \%$ in 1987 to $2.5 \%$ in 2009 , and the operative vaginal delivery rate declined from $6.3 \%$ to $3.9 \% .{ }^{17}$ The increase in obstetric trauma among operative vaginal deliveries in our population 
Table 4: Change in obstetric trauma and severe birth trauma rates per $1 \%$ absolute increase in operative vaginal delivery rates and associated number of excess cases per year*

Parous

\begin{tabular}{|c|c|c|c|c|c|c|}
\hline & \multicolumn{2}{|c|}{ Nulliparous } & \multicolumn{2}{|c|}{ No previous cesarean } & \multicolumn{2}{|c|}{ With a previous cesarean } \\
\hline & $\begin{array}{c}\text { ARR } \\
(95 \% \mathrm{Cl})\end{array}$ & $\begin{array}{l}\text { No. of excess } \\
\text { cases/yrt }\end{array}$ & $\begin{array}{c}\text { ARR } \\
(95 \% \mathrm{Cl})\end{array}$ & $\begin{array}{l}\text { No. of excess } \\
\text { cases/yrt }\end{array}$ & $\begin{array}{c}\text { ARR } \\
(95 \% \mathrm{Cl})\end{array}$ & $\begin{array}{l}\text { No. of excess } \\
\text { cases/yrt }\end{array}$ \\
\hline
\end{tabular}

Obstetric trauma

$\begin{array}{ccccc}1.06 & 708 & 1.10 & 360 & 1.11 \\ (1.05-1.06) & & (1.08-1.13) & & (1.07-1.16)\end{array}$

Operative instrument

$\begin{array}{lccc}\text { Forceps } & 1.09 & 1061 & 1.26 \\ & (1.08-1.10) & & (1.10-1.43) \\ \text { Vacuum } & 1.06 & 708 & 1.05 \\ & (1.05-1.07) & & (1.03-1.08) \\ \text { Sequential } & 1.44 & 5189 & 1.19 \\ & (1.35-1.55) & & (0.84-1.67)\end{array}$

937

1.11

158

(1.00-1.25)

180

1.16

(1.11-1.22)

0.95

(1.35-1.55)

(0.84-1.67)

(0.83-1.09)

Pelvic station

Outlet

1.07

825

1.22

(1.06-1.09)

Low

1.04

(1.03-1.05)

472

(1.14-1.30)

0.98

(0.93-1.03)

1.14

Midpelvic

1.07

825

(1.12-1.17)

18

0.98

(0.94-1.04)

793

1.17

(1.04-1.31)

1.02

(0.94-1.11)

1.25

(1.20-1.30)

360

\section{Severe birth trauma}

All OVD $\begin{gathered}1.05 \\ (1.03-1.07\end{gathered}$

Operative instrument

$\begin{array}{lc}\text { Forceps } & 1.01 \\ & (0.95-1.08) \\ \text { Vacuum } & 0.97 \\ & (0.90-1.04) \\ \text { Sequential } & 1.53 \\ & (1.03-2.27)\end{array}$

$-\quad 1.09$

(0.68-1.76)

0.96

(0.89-1.04)

191

2.00

(0.58-6.86)

1.02

(0.85-1.22)

Pelvic station

Outlet

1.03

0.91

(0.71-1.15)

Low

(0.96-1.10)

Midpelvic

1.06

(1.01-1.12)

1.04

1.18

(0.98-1.43)

(1.01-1.07)

0.94

(0.87-1.02)

0.86

(0.37-2.00)

1.25

(0.91-1.72)

0.47

(0.17-1.27)

1.27

(0.58-2.80)

0.87

(0.49-1.55)

1.12

(0.82-1.53)

Note: $A R R=$ adjusted rate ratio, $\mathrm{Cl}=$ confidence interval, $\mathrm{OVD}=$ operative vaginal delivery

${ }^{*}$ ARRs and $95 \% \mathrm{Cls}$ expressing the change in obstetric trauma and severe birth trauma rates per $1 \%$ absolute increase in OVD rates and associated number of excess cases per year, term singleton deliveries, Canada, 2004-2014; includes data from Alberta, Manitoba, Ontario, and Saskatchewan. Crude and adjusted rate ratios were obtained from ecological random-intercept Poisson regression models. Adjusted for rates of older maternal age ( $\geq 35$ years of age), hypertension, diabetes, labour induction, macrosomia ( $>4000 \mathrm{~g}$ ), and year of delivery.

†Number of excess cases of obstetric trauma and severe birth trauma in Canada annually, based on the number of births in Canada in $2015 / 16 .{ }^{13}$

occurred concomitantly, with an $11 \%$ decline in the rate of operative vaginal delivery in Canada over the study period. ${ }^{20}$ The temporal increase in adverse maternal outcomes among operative vaginal deliveries suggests that the safety of these procedures is declining in Canada, especially after forceps use. This trend may be due to a decline in expertise, to poor selection of candidates for operative vaginal delivery, ${ }^{21}$ or perhaps to operative vaginal delivery being reserved for the most severe cases.

\section{Limitations}

The limitations of our study include those that are typical of large database studies (such as data transcription errors). Also, our analyses were based on an ecological design and the quantified relationships are susceptible to the ecological fallacy. However, an ecological design is appropriate for assessing associations at the population level, ${ }^{22,23}$ and individual-level studies also show that operative vaginal deliveries cause obstetric and birth trauma. ${ }^{6-9}$ Measurement of pelvic 
station can be subjective and can be affected by moulding and fetal head position. ${ }^{24,25}$ Our estimates reflect the average trauma rates for outlet, low- and midpelvic procedure, as carried out under current norms of diagnosis by contemporary maternity care providers. Although we adjusted for rates of common pregnancy complications (viz., hypertension and diabetes), some uncommon complications may have been overrepresented in the cesarean delivery group. We did not have information on long-term outcomes, such as morbid placentation after cesarean delivery, which is particularly important for women planning large families. We were not able to account for clustering by multiple deliveries to the same woman, which may have had a small effect on the precision of our estimates. Finally, we were not able to adjust for trends in important maternal characteristics such as pre-pregnancy obesity, for which our data source lacked information.

\section{Conclusion}

The rates of obstetric trauma and severe birth trauma have increased among operative vaginal deliveries despite an overall decline in the use of operative vaginal delivery. There is a positive association between the population rate of operative vaginal delivery and population rates of obstetric trauma, and severe birth trauma in nulliparous women. Recommendations to reduce cesarean delivery rates by increasing rates of operative vaginal delivery should be tempered by the understanding that such actions may be associated with higher rates of obstetric trauma. Continued concerted efforts toward improving the recognition and management of obstetric anal sphincter injury are warranted.

\section{References}

1. Martin JA, Hamilton BE, Osterman MJK, et al. Births: final data for 2015. National Vital Statistics Report, Vol. 66, No. 1. Hyattsville (MD): National Center for Health Statistics; 2017

2. Martin JA, Hamilton BE, Osterman MJ, et al. Births: final data for 2012. Natl Vital Stat Rep 2013;62:1-68.

3. Health Canada. Canadian perinatal health report, 2003. Ottawa: Minister of Public Works and Government Services Canada; 2003.

4. Canadian perinatal health report, 2008 edition. Ottawa: Public Health Agency of Canada; 2008.

5. American College of Obstetricians and Gynecologists (College); Society for Maternal-Fetal Medicine; Caughey AB, Cahill AG, Guise JM, et al. Safe prevention of the primary cesarean delivery. Am J Obstet Gynecol 2014;210:179-93.

6. Muraca GM, Sabr Y, Lisonkova S, et al. Perinatal and maternal morbidity and mor- tality after attempted operative vaginal delivery at midpelvic station. CMAJ 2017;189:E764-72.

7. Muraca GM, Skoll A, Lisonkova S, et al. Perinatal and maternal morbidity and mortality among term singletons following midcavity operative vaginal delivery versus caesarean delivery. BJOG 2018;125:693-702.

8. Halscott TL, Reddy UM, Landy HJ, et al. Maternal and neonatal outcomes by attempted mode of operative delivery from a low station in the second stage of labor. Obstet Gynecol 2015;126:1265-72.

9. Bailit JL, Grobman WA, Rice MM, et al.; Eunice Kennedy Shriver National Institute of Child Health and Human Development Maternal-Fetal Medicine Units Network. Evaluation of delivery options for second-stage events. Am J Obstet Gynecol 2016;214:638.e1-10.

10. Joseph KS, Fahey J.; Canadian Perinatal Surveillance System. Validation of perinatal data in the Discharge Abstract Database of the Canadian Institute for Health Information. Chronic Dis Can 2009;29:96-100.

11. Data quality study of the 2015-2016 Discharge Abstract Database: a focus on hospital harm. Ottawa: Canadian Institute for Health Information; 2016.

12. Cunningham FG, Leveno KJ, Bloom SL, et al. Williams obstetrics. 23rd ed. New York: McGraw-Hill Medical; 2009.

13. CANSIM table 051-0004: Births, estimates, by province and territory [table]. Cat. no. 91-215-X. Ottawa: Statistics Canada (modified 2017 Sept. 27). Available: www.statcan. gc.ca/tables-tableaux/sum-som/101/cst01/demo04a-eng.htm (accessed 2017 Aug. 3).

14. Harvey MA, Pierce M, Alter JE, et al.; Society of Obstetricians and Gynaecologists of Canada. Obstetrical anal sphincter injuries (OASIS): Prevention, recognition, and repair. J Obstet Gynaecol Can 2015;37:1131-48.

15. Sultan AH, Kettle C. Diagnosis of perineal trauma. In: Sultan AH, Thakar R, Fenner DE, editors. Perineal and anal sphincter trauma. 1st ed. London (UK): Springer-Lerlag; 2009:13-9.

16. Wegnelius G, Hammarström M. Complete rupture of anal sphincter in primiparas: long-term effects and subsequent delivery. Acta Obstet Gynecol Scand 2011;90:258-63.

17. Lisonkova S, Lavery JA, Ananth CV, et al. Temporal trends in obstetric trauma and inpatient surgery for pelvic organ prolapse: an age-period-cohort analysis. Am J Obstet Gynecol 2016;215:208.e1-12.

18. Wen SW, Liu S, Kramer MS, et al. Comparison of maternal and infant outcomes between vacuum extraction and forceps deliveries. Am J Epidemio/ 2001;153:103-7.

19. Smith LA, Price N, Simonite V, et al. Incidence of and risk factors for perineal trauma: a prospective observational study. BMC Pregnancy Childbirth 2013;13:59.

20. Muraca GM, Sabr Y, Brant R, et al. Temporal and regional variations in operative vaginal delivery in Canada by pelvic station, 2004-2012. J Obstet Gynaecol Can 2016;38:627-35.

21. Dildy GA, Belfort MA, Clark SL. Obstetric forceps: a species on the brink of extinction. Obstet Gynecol 2016;128:436-9.

22. Susser M. The logic in ecological: I. The logic of analysis. Am J Public Health 1994;84:825-9.

23. Wen SW, Kramer MS. Uses of ecologic studies in the assessment of intended treatment effects. J Clin Epidemiol 1999;52:7-12.

24. Knight D, Newnham JP, McKenna M, et al. Comparison of abdominal and vaginal examinations for the diagnosis of engagement of the fetal head. Aust N Z J Obstet Gynaecol 1993;33:154-8.

25. Dupuis $\mathrm{O}$, Silveira R, Zentner A, et al. Birth simulator: reliability of transvaginal assessment of fetal head station as defined by the American College of Obstetricians and Gynecologists classification. Am J Obstet Gynecol 2005;192:868-74.

\section{Competing interests: None declared.}

This article has been peer reviewed.

Affiliations: School of Population and Public Health (Muraca, Lisonkova, Joseph); Department of Obstetrics \& Gynaecology (Muraca, Lisonkova, Skoll, Cundiff, Sabr, Joseph), University of British Columbia; BC Children's and Women's Hospital and Health Centre (Muraca, Lisonkova, Skoll, Brant, Cundiff, Joseph); Department of Statistics (Brant), University of British Columbia, Vancouver, BC; Department of Obstetrics and Gynaecology (Sabr), King Saud University, King Khalid University Hospital, Riyadh, Saudi Arabia

Contributors: Giulia Muraca and K.S. Joseph proposed the study concept and design, and were assisted by Sarka Lisonkova, Amanda Skoll, Rollin
Brant, Yasser Sabr and Geoffrey Cundiff. Giulia Muraca acquired the data and conducted the analyses. Sarka Lisonkova, Amanda Skoll, Rollin Brant, Yasser Sabr, Geoffrey Cundiff and K.S. Joseph reviewed the preliminary and final analyses. Giulia Muraca drafted the manuscript. All of the authors reviewed the manuscript critically for important intellectual content, gave final approval of the version to be published and agreed to be accountable for all aspects of the work.

Funding: Giulia Muraca is the recipient of a Vanier Canada Graduate Scholarship; K.S. Joseph is supported by the BC Children's Hospital Research Institute and holds a Canadian Institutes of Health Research (ClHR) Chair in maternal, fetal, and infant health services research (APR-126338). This study was funded by a CIHR grant on severe maternal morbidity (no. MAH-15445). Sarka Lisonkova is supported by a Scholar Award from the Michael Smith Foundation for Health Research.

Acknowledgement: Data for this study were provided by the Canadian Institute for Health Information (ClHI). However, the analyses, conclusions and opinions expressed herein are those of the authors and not those of $\mathrm{CIHI}$.

Disclaimer: Rollin Brant was a biostatistical consultant for CMAJ at the time of submission and was not involved in the editorial decision-making process for this article.

Accepted: May 7, 2018

Correspondence to: Giulia Muraca, gmuraca@bcchr.ca 